\title{
Use of an arrayed promoter-probe library for the identification of macrophage-regulated genes in Mycobacterium tuberculosis
}

\author{
Russell J. Hobson, ${ }^{1} \dagger$ Alan J. A. McBride, ${ }^{1} \neq$ Karen E. Kempsell ${ }^{2}$ \\ and Jeremy W. Dale ${ }^{1}$
}

Author for correspondence: Jeremy W. Dale. Tel: +44 1483 686484. Fax: +44 1483300374. e-mail: j.dale@surrey.ac.uk

1 School of Biomedical and Life Sciences, University of Surrey, Guildford, Surrey GU2 7XH, UK

2 GlaxoSmithKline Research and Development, Gunnels Wood Road, Stevenage, Hertfordshire SG1 2NY, UK
The survival of Mycobacterium tuberculosis within the human host after infection, especially within macrophages, is likely to require the activation of a number of mycobacterial genes. To identify such genes, a promoter-probe library was constructed in which fragments of $M$. tuberculosis H37Rv DNA were inserted upstream of a lacZ reporter gene, using an Escherichia coli-mycobacterial shuttle vector. Mycobacterium bovis Bacille Calmette-Guérin (BCG) was subsequently transformed with this library and 4800 BCG clones were arrayed in a 96-well microtitre format, enabling the testing of individual clones for promoter activity under a variety of conditions. From preliminary screening, 41 clones were selected that exhibited upregulation of lac $Z$ expression when subjected to acidified sodium nitrite. Subsequent sequence analyses identified 26 of these clones as containing potential promoters. After measuring lacZ expression in BCG clones recovered from a THP-1 macrophage cell line, three genes were selected for assessment of their expression in $M$. tuberculosis during macrophage infection, by realtime RT-PCR. Two of these genes, Rv1265 (with unknown function) and Rv2711 (encoding the iron-dependent repressor protein IdeR), showed evidence of being upregulated within macrophages.

Keywords: gene expression, virulence, promoters

\section{INTRODUCTION}

Tuberculosis remains one of the most important infectious bacterial diseases in the world, yet there are many aspects of its infection process that are imperfectly understood. Although a number of candidate virulence genes have been identified, direct evidence that they are necessary for virulence is only available in a limited number of cases, e.g. katG (Zhang \& Young, 1993), rpoV (Collins et al., 1995), isocitrate lyase (McKinney et al., 2000), the exported repetitive protein erp gene (Berthet et al., 1998) and the putative cell entry mce genes (Arruda et al., 1993).

\footnotetext{
†Present address: URC Neuroendocrinology, Bristol Royal Infirmary, Marlborough Street, Bristol BS1 8HW, UK.

$\ddagger$ Present address: Microbiology and Immunobiology Department, School of Medicine, Queens University of Belfast, Grosvenor Road, Belfast BT12 $6 \mathrm{BN}$, Ireland.

Abbreviation: $\mathrm{BCG}$, Bacille Calmette-Guérin.
}

Central to the search for additional virulence determinants is the concept that a number of mycobacterial genes are likely to be activated or upregulated when Mycobacterium tuberculosis enters a macrophage. A variety of methods have been used for identifying mycobacterial genes that are selectively expressed within macrophages or that are identified as virulence determinants by other criteria [see, for example, Plum \& Clark-Curtiss (1994), Lee \& Horwitz (1995), Rindi et al. (1999) and Graham \& Clark-Curtiss (1999), and reviews by Gomez \& Smith (2000), Collins \& Gicquel (2000) and Timm et al. (1999)]. Promoter-probe approaches, in which random or specific fragments of mycobacterial DNA are tested for their ability to drive the expression of reporter genes such as $\beta$-galactosidase or green fluorescent protein, have been especially widely used [see, for example, Dellagostin et al. (1995), Barker et al. (1998), Tyagi et al. (2000) and Triccas et al. (1999, 2001)].

In this paper, we describe the construction of an arrayed 
library of M. tuberculosis DNA fragments in a promoter-probe vector and its use for rapid screening for potential promoters that respond to various environmental conditions, including those that may be encountered within macrophages.

\section{METHODS}

Bacterial strains and plasmids. M. tuberculosis $\mathrm{H} 37 \mathrm{Rv}$ (ATCC 27294) and Mycobacterium bovis Bacille CalmetteGuérin (BCG) Pasteur (ATCC 35748) were grown in Middlebrook $7 \mathrm{H} 9$ liquid medium for 7 days or on $7 \mathrm{H} 11$ agar plates for 21 days. Solid and liquid media were supplemented with $5 \%$ (v/v) OADC (Becton Dickenson); $0.05 \%$ (w/v) Tween 80 was also added to the liquid medium. Kanamycin was added to the media at $15 \mu \mathrm{g} \mathrm{ml}^{-1}$ for BCG and at $50 \mu \mathrm{g} \mathrm{ml}^{-1}$ for Escherichia coli. X-Gal was added to the media at $50 \mu \mathrm{g} \mathrm{ml}^{-1}$.

The promoter-probe vector pUS1800 (see Fig. 1) was derived by inserting the entire (promoterless) lacZ-coding region, amplified from pMC1871 (Promega) using a primer to insert a NarI site adjacent to the start codon, into the shuttle vector pUS1781 (G. R. Stewart, unpublished data). The lacZ gene was orientated to transcribe away from the T4 terminator. The mycobacterial origin of replication is contained on a $1.6 \mathrm{~kb}$ fragment derived from pAL5000 (Ranes et al., 1990).

Gene-library construction. An M. tuberculosis H37Rv genomic DNA preparation was divided into three aliquots and each was subjected to partial digestion with a different restriction enzyme (AciI, HpaII or TaqI). The individual digests were gel purified to generate DNA fragments of between 0.3 and $1.0 \mathrm{~kb}$. These were then pooled and ligated with NarI-digested pUS1800. Epicurean Coli XL2-Blue ultracompetent cells (Stratagene) were transformed with the library and then plated onto $\mathrm{L}$ agar (Bacto tryptone, $1 \%$; yeast

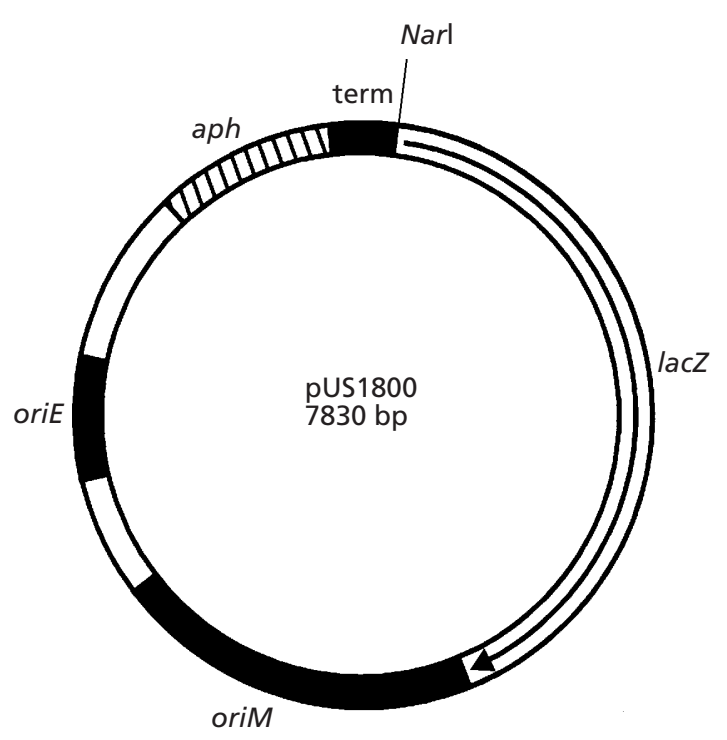

Fig. 1. Plasmid map of pUS1800. oriE, E. coli origin of replication (pUC19); oriM, mycobacterial origin of replication $(1.6 \mathrm{~kb}$ fragment from pAL5000); aph, kanamycin-resistance gene (aminoglycoside phosphotransferase, Tn903); term, T4 transcriptional terminator; lacZ, reporter gene, amplified by PCR from pMC1871 using a primer to introduce a Narl site adjacent to the start codon. extract, $0.5 \%$; NaCl, $85 \mathrm{mM} ; \mathrm{pH} 7 \cdot 5)$. Plasmid DNA was recovered from a pool of greater than $1 \times 10^{5}$ clones. $M$. bovis BCG Pasteur was then electroporated with the pooled, purified M. tuberculosis $\mathrm{H} 37 \mathrm{Rv}$ plasmid library and clones were recovered on $7 \mathrm{H} 11$ medium containing kanamycin. A selection of 4800 individual clones was picked and arrayed in 50 96-well microtitre trays. A master library and sub-libraries of clones were stored at $-70{ }^{\circ} \mathrm{C}$.

Gene-library screening. One set of microtitre trays, containing 4800 clones, was subcultured, using a 96-pin replicator, into $7 \mathrm{H} 9$ broth at $\mathrm{pH} 6.6$ (control), $7 \mathrm{H} 9$ broth at $\mathrm{pH} 5.4$ (control) and $7 \mathrm{H} 9$ broth at $\mathrm{pH} 5.4$ containing fresh sodium nitrite $(0.5$ $\mathrm{mM})$, and also onto equivalent $7 \mathrm{H} 11$ agar plates. All media contained X-Gal. After incubation at $37^{\circ} \mathrm{C}$ for 7 days (liquid media) or 20 days (solid media), the clones were scored for their levels of expression of $\beta$-galactosidase by visual comparison of the blue colour produced to a standard scale.

Selected clones were inoculated individually into $7 \mathrm{H} 9$ broth and grown at $37^{\circ} \mathrm{C}$, without shaking, for 4 days. They were then subcultured into $7 \mathrm{H} 9$ broth at $\mathrm{pH} 6.6$ (control), $7 \mathrm{H} 9$ broth at $\mathrm{pH} 5 \cdot 4$ (control) and $7 \mathrm{H} 9$ broth at $\mathrm{pH} 5 \cdot 4$ containing sodium nitrite, as before. After 4 days incubation at $37^{\circ} \mathrm{C}$, $0.5 \mathrm{ml}$ of each broth culture was removed for measurement of the optical density at $600 \mathrm{~nm}$, and a further $0.5 \mathrm{ml}$ sample was used for the $\beta$-galactosidase assay, as described below.

$\beta$-Galactosidase assay with Galacto-Light Plus as substrate. For cell disruption, $0.5 \mathrm{ml}$ of each mycobacterial culture was added to a Hybaid Ribolyser blue tube containing 0.5 ml PBS ( NaCl, $137 \mathrm{mM}$; KCl, $2.7 \mathrm{mM}$; $\mathrm{Na}_{2} \mathrm{HPO}_{4}, 4.3 \mathrm{mM} ; \mathrm{KH}_{2} \mathrm{PO}_{4}$, $1.4 \mathrm{mM}$; pH 7.3), with fresh DTT added to a final concentration of $0.5 \mathrm{mM}$. Each sample was then subjected to shear lysis in a Hybaid Ribolyser at speed 5.0 for $45 \mathrm{~s}$. The Ribolyser tubes, containing the lysed bacteria, were cooled on ice for $1 \mathrm{~min}$ and then stored at $-80^{\circ} \mathrm{C}$, to be used at a later date. The bacterial extracts were thawed at $4{ }^{\circ} \mathrm{C}$ and then centrifuged at $15000 \mathrm{~g}$ for $5 \mathrm{~min}$, to sediment the cell debris. The Galacto-Light Plus (Tropix) assay was carried out, according to the manufacturer's instructions, using $20 \mu \mathrm{l}$ of the supernatant. The initial culture density was determined either by measuring the $\mathrm{OD}_{600}$ value or by plating out small samples of cultures on selective $7 \mathrm{H} 11$ media. The $\beta$-galactosidase activity was expressed as light units $\left(1 \times 10^{3}\right.$ bacterial cells $)^{-1}$. A single culture was used for the screening experiment. For subsequent experiments with the selected clones, results were expressed as the mean of three independent cultures.

Infection of the macrophage cell line. Human THP-1 macrophage (ATCC TIB 202) cells were cultured in Dul-

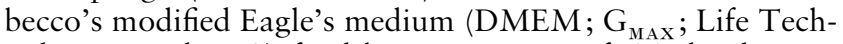
nologies) with $10 \%$ fetal bovine serum (Life Technologies). THP-1 cells were differentiated by incubation for 3 days in 24-well plates in $0.5 \mathrm{ml}$ of culture medium containing $5 \mathrm{ng}$ phorbol myristate acetate $\mathrm{ml}^{-1}$, which was removed and replaced with fresh DMEM plus $10 \%$ fetal calf serum prior to infection of the macrophage cells by the addition of M. bovis BCG Pasteur clones at an m.o.i. of 10. After the required length of time (at least $2 \mathrm{~h}$ ), the medium was removed and the THP-1 cells were washed twice with $0.5 \mathrm{ml}$ of PBS, to remove extracellular bacteria. The THP-1 cells were then disrupted with $0.0025 \%(\mathrm{w} / \mathrm{v})$ SDS. The number of BCG cells in the lysate was estimated by viable counts of serial dilutions, and the $\beta$-galactosidase levels were assayed by the Galacto-Light Plus procedure following disruption of the bacteria, as described above. The $\beta$-galactosidase activity was expressed as light units $\left(1 \times 10^{3} \text { bacterial cells }\right)^{-1}$, using the mean of three independent THP-1 infections. The significance of the differ- 
Table 1. Primers used for real-time RT-PCR

\begin{tabular}{|c|c|c|}
\hline Primer & Gene amplified & Sequence \\
\hline $302-5^{\prime}$ & Rv0302 & GGGAGAGGTCACGAGAATCG \\
\hline $302-3^{\prime}$ & Rv0302 & AGCCCTTGGTCGCCATC \\
\hline $1265-5^{\prime}$ & Rv1265 & GACTGGTTCGACGGCGAC \\
\hline $1265-3^{\prime}$ & Rv1265 & GCTTGCCAATCACCGTAATTTC \\
\hline $2711-5^{\prime}$ & Rv2711 & AGCACGTGATGAGCGAGGAC \\
\hline $2711-3^{\prime}$ & Rv2711 & TGGTCGGGTTGTTGAGCAC \\
\hline SIGA-5' & $\mathrm{Rv} 2703 / r p o \mathrm{~V}$ & TTCGCGCCTACCTCAAACAG \\
\hline SIGA-3' & Rv2703/rpoV & GCTAGCTCGACCTCTTCCTCG \\
\hline
\end{tabular}

ence between in vitro culture and THP-1 infection was tested using a $t$-test, after transforming the results to $\log _{10}$ values.

Sequencing of each clone. The M. tuberculosis H37Rv DNA insert in the selected clones was amplified by PCR, using primers from the flanking vector sequence, and sequenced bidirectionally. The DNA sequences identified were compared against the $M$. tuberculosis H37Rv genome sequence (Cole et al., 1998; http://www.sanger.ac.uk/Projects/M_tuberculosis/) using BLAST (http://www.ncbi.nlm.nih.gov/BLAST/).

Quantitative real-time RT-PCR. All primers used for the quantitative real-time RT-PCR were designed on the Primer Express software (version 1.0; Perkin Elmer) (see Table 1). RNA was obtained from $M$. tuberculosis H37Rv after culturing in either $7 \mathrm{H} 9$ liquid medium or DMEM plus serum (controls), and from $M$. tuberculosis $\mathrm{H} 37 \mathrm{Rv}$ recovered from THP-1 cells (m.o.i. of 10). After the required length of time, the controls were pelleted (centrifugation at $3000 \mathrm{~g}$ for $10 \mathrm{~min}$ ) and resuspended in $500 \mu \mathrm{l}$ of $4 \mathrm{M}$ acidified guanidinium isothiocyanate. Macrophages were lysed by the addition of $4 \mathrm{M}$ acidified guanidinium isothiocyanate, and the $M$. $t u$ berculosis H37Rv was pelleted and resuspended in $500 \mu \mathrm{l}$ of $4 \mathrm{M}$ acidified guanidinium isothiocyanate. The bacterial suspension was added to a mixture containing $500 \mu \mathrm{l}$ acidified phenol, $100 \mu$ l chloroform/isoamyl alcohol $(24: 1, \mathrm{v} / \mathrm{v})$ and $200 \mu \mathrm{l}$ acidified Divolab no. 1 (Diversey). It was then processed immediately in a Hybaid Ribolyser at speed 4.0 for $40 \mathrm{~s}$ and cooled on ice for $1 \mathrm{~min}$. Cell debris was removed by centrifugation, and the aqueous layer was extracted with an equal volume of chloroform/isoamyl alcohol $(24: 1, \mathrm{v} / \mathrm{v})$. The aqueous layer was then transferred to a fresh tube and the RNA was precipitated with $500 \mu \mathrm{l}$ of a 2-propanol/3 M sodium acetate/linear acrylamide solution $(0 \cdot 3 \mathrm{ml} 3 \mathrm{M}$ sodium acetate, $\mathrm{pH} 4 \cdot 0 ; 49.7 \mathrm{ml}$ 2-propanol; $50 \mathrm{ng}$ linear acrylamide). The precipitate was resuspended in diethyl-pyrocarbonatetreated water. The total RNA levels of each preparation were estimated by comparison to a standard RNA marker (Promega), using gel electrophoresis to visualize the RNA. RNA levels amongst the preparations were then adjusted to provide equivalent amounts of RNA for RT-PCR. As an additional control, Rv2703 (SigA/rpoV) was included as an example of a gene that is not considered to be upregulated during infection (Manganelli et al., 1999). The RNA preparations were treated with excess RNase-free DNase and reverse transcribed using random hexamer primers (Gibco-BRL). The SYBR Green reporter system (Perkin Elmer) was used, as described by the manufacturer, and all real-time PCRs were carried out on an ABI PRISM 7700 Sequence Detection System (Perkin Elmer) using MicroAmp Optical 96-Well Reaction Plates and Optical Caps (Perkin Elmer). The following PCR conditions were used: 40 cycles at $60^{\circ} \mathrm{C}$ for $30 \mathrm{~s}$ and $95^{\circ} \mathrm{C}$ for $30 \mathrm{~s}$. The $C_{\mathrm{T}}$ values (number of cycles needed for a detectable signal) were converted to amounts of cDNA template by using standard curves for each primer pair.

\section{RESULTS}

\section{Library construction and preliminary screening}

A library of partially digested M. tuberculosis $\mathrm{H} 37 \mathrm{Rv}$ genomic DNA was constructed in the shuttle promoterprobe vector pUS1800 (Fig. 1), as described in Methods. The mean size of the inserted DNA fragment in a sample of the library of transformed E. coli clones (as determined by PCR) was $400 \mathrm{bp}$, with the maximum and minimum insert sizes being $1.5 \mathrm{~kb}$ and $150 \mathrm{bp}$, respectively. Plasmid DNA was purified from pooled E. coli transformants and, after electroporation of $M$. bovis BCG Pasteur with the amplified plasmid library, 4800 random individual BCG clones were picked and arrayed in a 96-well format.

To enrich the library for a subset of the promoters that are potentially upregulated within macrophages, preliminary screening of the library was carried out using acidified sodium nitrite $\left(0.5 \mathrm{mM} \mathrm{NaNO}_{2}\right.$ at $\left.\mathrm{pH} 5 \cdot 4\right)$, to represent one of the potential stimuli that may affect mycobacterial gene expression within macrophages. The arrayed library was replicated in liquid and solid media containing X-Gal, and the level of lacZ expression of each clone was estimated visually by comparison to a standard colour chart.

In this initial screen, 300 clones were identified (200 from liquid media and 100 from agar plates) which appeared to exhibit different levels of lac $Z$ expression in the presence of acidified sodium nitrite, compared to the controls at $\mathrm{pH} 5 \cdot 4$ and $6 \cdot 6$. These clones were retrieved from the master plates and were assayed individually, using the Galacto-Light Plus procedure described in Methods. Amongst those clones subsequently identified as likely to contain natural promoters (see Table 2), greater than 10 -fold induction was observed for clone 302 (Rv1852; UreG) at low pH, and greater than 10-fold induction was observed for clones 222 (Rv3174; putative oxidoreductase), 234 (Rv2921c; FtsY) and 281 (Rv1658; ArgG) in the presence of acidified sodium nitrite. Clone 320 (Rv0457c) showed apparent induction under both conditions, but from an almost undetectable base level. 
Table 2. Identity of promoter clones and macrophage induction of the reporter gene

The results below are representative for a single culture of THP-1 cells assayed in triplicate. BCG clones shown in bold were subsequently analysed further. All M. tuberculosis gene identity, gene location and gene product details were obtained from the Sanger Centre M. tuberculosis H37Rv genome site (www.sanger.ac.uk/Projects/M_tuberculosis/).

\begin{tabular}{|c|c|c|c|c|c|c|c|c|c|}
\hline \multicolumn{10}{|c|}{ BCG clones containing potential natural promoters from $M$. tuberculosis } \\
\hline \multirow[t]{2}{*}{ Clone } & \multicolumn{2}{|c|}{$\begin{array}{l}\text { In vitro induction in } 7 \mathrm{H} 9 \\
\text { medium at }\end{array}$} & \multicolumn{2}{|c|}{$\begin{array}{l}\text { Macrophage induction } \\
\text { ratio at } †\end{array}$} & \multirow[t]{2}{*}{$\begin{array}{c}\text { Insert size } \\
\quad(n t)\end{array}$} & \multicolumn{2}{|c|}{$\begin{array}{l}\text { Location on } M . \text { tuberculosis } \\
\text { H37Rv genome (nt) }\end{array}$} & \multirow[t]{2}{*}{ Gene } & \multirow[t]{2}{*}{ Gene product } \\
\hline & $\mathrm{pH} 5 \cdot 4$ & $\begin{array}{c}\mathrm{pH} \mathrm{5.4} \\
+\mathrm{NaNO}_{2}\end{array}$ & $\begin{array}{c}2 \mathrm{~h} \\
\text { post-infection }\end{array}$ & $\begin{array}{c}24 \mathrm{~h} \\
\text { post-infection }\end{array}$ & & $5^{\prime}$ & $3^{\prime}$ & & \\
\hline 13 & Y & & $10 \cdot 4 \rrbracket$ & $9 \cdot 0$ & 865 & 551479 & 552343 & $(\mathrm{Rv} 0460 / 1) \ddagger$ & $\begin{array}{l}\text { Hypothetical protein/possible membrane } \\
\text { protein }\end{array}$ \\
\hline 63 & & Y & $177 \cdot 9 \|$ & $5 \cdot 3$ & 406 & 1051741 & 1051336 & Rv0940c & Probable monooxygenase \\
\hline 166 & & $\mathrm{Y}$ & $111 \cdot 3 \|$ & $13 \cdot 4 \|$ & 361 & 528230 & 528590 & Rv0440 & GroEL2, $60 \mathrm{kDa}$ chaperonin 2 \\
\hline 169 & Y & Y & $64 \cdot 8 \|$ & $4 \cdot 5 \$$ & 524 & 1166888 & 1167411 & Rv1044 & Conserved hypothetical protein \\
\hline 175 & $\mathrm{Y}$ & & $115 \cdot 0 \|$ & $1 \cdot 8$ & 395 & 364222 & 364616 & Rv0302 & $\begin{array}{l}\text { Transcriptional regulator (TetR/AcrR } \\
\text { family) }\end{array}$ \\
\hline 176 & Y & & $98 \cdot 8 \|$ & $10 \cdot 6 \mathbb{S}$ & 259 & 3023359 & 3023617 & Rv2711 & IdeR, iron-dependent repressor \\
\hline 180 & Y & Y & $115 \mathbb{S}$ & $18 \cdot 6 \mathbb{S}$ & 271 & 1293907 & 1294177 & Rv1165 & Conserved hypothetical protein \\
\hline 188 & Y & & $4 \cdot 7$ & $2 \cdot 4$ & 482 & 1623822 & 1623341 & Rv1444c & Hypothetical protein \\
\hline 205 & & Y & $5 \cdot 0$ & $0 \cdot 01 \|$ & 543 & 860532 & 861074 & $\mathrm{Rv} 0767 \mathrm{c}$ & Hypothetical protein \\
\hline 222 & $\mathrm{Y}$ & Y & $1 \cdot 2$ & $0 \cdot 2 \rrbracket$ & 298 & 3541887 & 3542184 & Rv3174 & Putative oxidoreductase \\
\hline 226 & & Y & $1 \cdot 3$ & $1 \cdot 5$ & 261 & 2925616 & 2925356 & Rv2594c & $\begin{array}{l}\text { Holliday junction resolvase, } \\
\text { endodeoxyribonuclease }\end{array}$ \\
\hline 233 & Y & & $0 \cdot 7$ & $7 \cdot 2$ & 165 & 1446456 & 1446292 & $\mathrm{tRNA}_{\mathrm{ArgV}}$ & tRNA \\
\hline 234 & Y & $\mathrm{Y}$ & $0 \cdot 03 \mathbb{S}$ & $0 \cdot 6$ & 781 & 3234534 & 3233754 & Rv2921c & Cell-division protein FtsY \\
\hline 239 & $\mathrm{Y}$ & $\mathrm{Y}$ & $108 \cdot 6 \mathbb{S}$ & $0.02 \$$ & 253 & 1413241 & 1413493 & Rv1265 & Hypothetical protein \\
\hline 254 & Y & & $5 \cdot 2$ & $1 \cdot 9$ & 662 & 213879 & 214540 & Rv0183 & Probable oxidoreductase \\
\hline 277 & Y & & $1 \cdot 4$ & $0 \cdot 1 \|$ & 261 & 2623709 & 2623969 & Rv2345 & Precursor of probable membrane protein \\
\hline 278 & Y & Y & $2 \cdot 4$ & $0 \cdot 4$ & 303 & 528230 & 528532 & Rv0440 & GroEL2, $60 \mathrm{kDa}$ chaperonin 2 \\
\hline 279 & Y & & $2 \cdot 4$ & $0 \cdot 0 \|$ & 316 & 1833418 & 1833733 & Rv1630 & RpsA, 30 S ribosomal protein $\mathrm{S} 1$ \\
\hline 281 & Y & Y & $5 \cdot 5$ & $<1$ & 295 & 1871235 & 1871529 & Rv1658 & ArgG, argininosuccinate synthase \\
\hline 289 & Y & Y & - & - & 196 & 2698200 & 2698395 & Rv2402 & Conserved hypothetical protein \\
\hline 291 & Y & Y & $0 \cdot 4$ & $<1$ & 303 & 528230 & 528532 & Rv0440 & GroEL2, $60 \mathrm{kDa}$ chaperonin 2 \\
\hline 292 & & Y & $1 \cdot 2$ & $<1$ & 494 & 417058 & 417551 & Rv0347 & Conserved hypothetical protein \\
\hline 302 & Y & Y & $0 \cdot 1$ & 1.5 & 346 & 2101154 & 2100809 & Rv1852 & UreG, urease accessory protein \\
\hline 320 & Y & Y & $10 \cdot 9$ & $2 \cdot 6$ & 230 & 549785 & 549556 & Rv0457c & Probable peptidase \\
\hline 325 & Y & & $<1$ & $<1$ & 503 & 1236475 & 1235973 & Rv1109c & Hypothetical protein \\
\hline 330 & Y & $\mathrm{Y}$ & $<1$ & $<1$ & 597 & 2614036 & 2614632 & Rv2339 & Conserved large membrane protein \\
\hline
\end{tabular}

BCG clones containing potential natural promoters from $M$. tuberculosis

\begin{tabular}{|c|c|c|c|c|c|c|c|c|}
\hline \multirow[t]{2}{*}{ Clone } & \multicolumn{2}{|c|}{$\begin{array}{c}\text { In vitro induction in } 7 \mathrm{H} 9 \\
\text { medium at }\end{array}$} & \multicolumn{2}{|c|}{$\begin{array}{l}\text { Macrophage induction } \\
\text { ratio at } \dagger\end{array}$} & \multirow[t]{2}{*}{$\begin{array}{c}\text { Insert size } \\
\quad(\mathrm{nt})\end{array}$} & \multicolumn{2}{|c|}{$\begin{array}{l}\text { Location on M. tuberculosis } \\
\text { H37Rv genome (nt) }\end{array}$} & \multirow[t]{2}{*}{ Gene } \\
\hline & pH 5.4 & $\begin{array}{l}\mathrm{pH} \mathrm{5.4} \\
+\mathrm{NaNO}_{2}\end{array}$ & $\begin{array}{c}2 \mathrm{~h} \\
\text { post-infection }\end{array}$ & $\begin{array}{c}24 \mathrm{~h} \\
\text { post-infection }\end{array}$ & & $5^{\prime}$ & $3^{\prime}$ & \\
\hline 7 & Y & & $23 \cdot 9 \|$ & $3 \cdot 0$ & 233 & 1699856 & 1699624 & Internal to $\mathrm{Rv} 1508 \mathrm{c}$ \\
\hline 89 & Y & & $>1$ & $>1$ & 243 & 905242 & 905484 & Internal to Rv0811c \\
\hline 90 & Y & Y & $14 \cdot 7 \|$ & $>1$ & 251 & 704074 & 704324 & $\begin{array}{l}\text { Intergenic; converging genes Rv0609 and } \\
\text { Rv0610c }\end{array}$ \\
\hline 200 & & Y & $80 \cdot 7 \|$ & $0 \cdot 7$ & 710 & 988370 & 987661 & Internal to Rv0888 \\
\hline 201 & $\mathrm{Y}$ & Y & $1 \cdot 6$ & $>1$ & 183 & 4192023 & 4191841 & Internal to Rv3740 \\
\hline 230 & $\mathrm{Y}$ & & $4 \cdot 5$ & $>1$ & 238 & 4398358 & 4398121 & Internal to Rv3910 \\
\hline 247 & Y & & - & - & 643 & 3210204 & 3209562 & Internal to Rv2900c \\
\hline 252 & $\mathrm{Y}$ & $\mathrm{Y}$ & - & $>1$ & 390 & 638568 & 638179 & Internal to Rv0547c \\
\hline 290 & $\mathrm{Y}$ & & - & - & 252 & 1289198 & 1288947 & Internal to Rv1161 \\
\hline 293 & $\mathrm{Y}$ & $\mathrm{Y}$ & - & - & 214 & 1901144 & 1901357 & Internal to Rv1676 \\
\hline 296 & $\mathrm{Y}$ & $\mathrm{Y}$ & $0 \cdot 7$ & $0 \cdot 3$ & 284 & 1541494 & 1541777 & Internal to Rv1368 \\
\hline 303 & $\mathrm{Y}$ & & $24 \cdot 8$ & $23 \cdot 9$ & 326 & 4306610 & 4306285 & Internal to Rv2832c \\
\hline 305 & $\mathrm{Y}$ & & $16 \cdot 3$ & $8 \cdot 1$ & 252 & 3424136 & 3423885 & Internal to Rv3061c \\
\hline 311 & $\mathrm{Y}$ & & $2 \cdot 2$ & $2 \cdot 4$ & 326 & 4306610 & 4306285 & Internal to Rv3832c \\
\hline 323 & $\mathrm{Y}$ & $\mathrm{Y}$ & $0 \cdot 4$ & $0 \cdot 1 \|$ & 449 & 601775 & 601327 & Internal to Rv0509 \\
\hline
\end{tabular}

*Y, BCG clones showing induction ratios $>3$ when grown in $7 \mathrm{H} 9$ broth at $\mathrm{pH} 5 \cdot 4$ and in $7 \mathrm{H} 9$ broth (pH $5 \cdot 4$ ) containing $0.5 \mathrm{mM}$ sodium nitrite, when compared to the control at $\mathrm{pH} 6.6$.

† Ratio calculated by dividing the $\beta$-galactosidase level per cell in macrophage-derived bacteria by that found in bacteria grown in DMEM plus serum. Values shown as $<1$ or $>1$ indicate that one of the expression values was too low to calculate a reliable induction ratio; - , both expression levels were too low to measure reliably.

¥ The insert in clone 13 contains the whole of Rv0460 (plus upstream sequence) and the start of Rv0461. It therefore potentially contains two promoters. 
It should be remembered that these data do not necessarily reflect the behaviour of these promoters in their natural environment.

The design of this experiment precludes accurate quantitative comparisons of promoter strength between clones, but it is worth noting that clone 233 produced much higher levels of $\beta$-galactosidase activity under control conditions than any other clone (including a positive control carrying a characterized hsp60 promoter). This clone contains most of the intergenic region between $\arg V$ (encoding $\mathrm{tRNA}_{\mathrm{Arg}}$ ) and $\operatorname{argS}$ (encoding arginyl-tRNA synthetase; Rv1292), and is oriented towards $\operatorname{argV}$. Although this promoter did not show significant induction, it may prove to be useful as a strong constitutive promoter for gene expression in mycobacteria.

Of the 300 clones screened, 43 exhibited an apparent induction ratio of greater than 3 at $\mathrm{pH} 5 \cdot 4$, when compared to the control at $\mathrm{pH} 6 \cdot 6$, whereas 31 showed an apparent induction ratio of greater than 3 in acidified sodium nitrite. In total, 53 clones showed this level of apparent induction under one or both conditions. These 53 clones were selected for further investigation, but 12 of them failed to grow and were discarded. Consequently, 41 clones were studied further (identified in Table 2).

\section{Sequence data}

The M. tuberculosis H37Rv DNA inserts in each of the $41 \mathrm{M}$. bovis BCG clones were sequenced bi-directionally, and their identity and location within the M. tuberculosis genome was determined by comparison with the complete $M$. tuberculosis $\mathrm{H} 37 \mathrm{Rv}$ genome sequence (Table 2).

Of the sequenced clones, 15 contained fragments of $M$. tuberculosis H37Rv DNA that were considered unlikely to represent natural promoters, since they were either entirely internal to predicted ORFs or, as in one case, comprised an intergenic region of $M$. tuberculosis H37Rv DNA located between two converging genes. However, it is possible that at least some of these clones do contain genuine promoters - it is not impossible for a genuine promoter to exist within a coding sequence and, in addition, the actual translated sequences may differ from the ORFs predicted in the genome sequence due to the use of alternative translational start sites. It should be noted that clone 7 in particular, which contains a fragment internal to the predicted ORF Rv1508c, was amongst the most active of the promoterprobe clones, and that inspection of the M. tuberculosis $\mathrm{H} 37 \mathrm{Rv}$ genome sequence shows a potential ribosomebinding site and start codon at this position within the predicted Rv1508c region.
The remaining 26 clones all contained sequence upstream from predicted $M$. tuberculosis $\mathrm{H} 37 \mathrm{Rv}$ genes that was in the correct orientation for driving the expression of the lacZ reporter gene on the plasmid. They can therefore be regarded as containing putative genuine promoters.

\section{$\beta$-Galactosidase expression in macrophages}

The 41 BCG clones that showed an induction ratio of greater than 3 were used to infect cultures of human and mouse macrophage-like cell lines (THP-1 and J774 cells, respectively). At 2 and $24 \mathrm{~h}$ post-infection, bacteria were recovered from infected macrophages and were assayed for $\beta$-galactosidase activity, using Galacto-Light Plus. Control cultures of the BCG clones in DMEM plus serum were also assayed at 2 and $24 \mathrm{~h}$ post-inoculation. $M$. bovis BCG carrying the parental, promoterless plasmid pUS1800 was used as a negative control. There was no detectable $\beta$-galactosidase expression from $M$. bovis BCG carrying the parental, promoterless, plasmid pUS1800, when grown under any of these conditions. The results obtained with THP-1 cells are presented in Table 2 in the form of induction ratios at 2 and $24 \mathrm{~h}$ post-infection, using a single culture (assayed in triplicate) in each case. Of the 41 clones, 11 showed a significantly higher $(P<0.01)$ level of $\beta$-galactosidase activity when grown in THP- 1 cells than when grown in DMEM plus serum, at one or both time points. Ten of these 11 clones (the exception being clone 200) also showed significant induction of $\beta$-galactosidase activity in the mouse macrophage cell line, J774 (data not shown). Since the effects on induction were similar in both types of cells, subsequent experiments were carried out with THP-1 cells only.

Eight clones that showed significant upregulation of $\beta$ galactosidase activity in THP-1 cells (compared to the DMEM plus serum control) contained gene fragments that represented potential natural promoters (Table 2 ). These eight clones represented approximately $20 \%(8$ out of 41) of the clones selected by the enrichment procedure.

The set of clones showing upregulation of $\beta$-galactosidase expression in THP-1 cells included clone 166, whose sequence contained a region upstream from $\mathrm{Rv} 0440$ (bsp60/groEL2). The expression of Rv0440 has been shown to be upregulated during infection (Batoni et al., 1998). However, two further clones (278 and 291) carrying fragments upstream from Rv0440 did not show significant induction upon infection of THP-1 cells. Although all three clones contain the transcription start sites identified by Stover et al. (1991), the two latter clones, which are identical, carry a shorter insert than

$\mathbb{S} P<0.01$ for the significance levels of the difference between the $\beta$-galactosidase level per cell in macrophage-derived bacteria when divided by that found in bacteria cultured in DMEM plus serum.

$\| P<0 \cdot 001$ for the significance levels of the difference between the $\beta$-galactosidase level per cell in macrophage-derived bacteria when divided by that found in bacteria cultured in DMEM plus serum.

I Clone 188 has a second insert, internal to Rv3856c. 


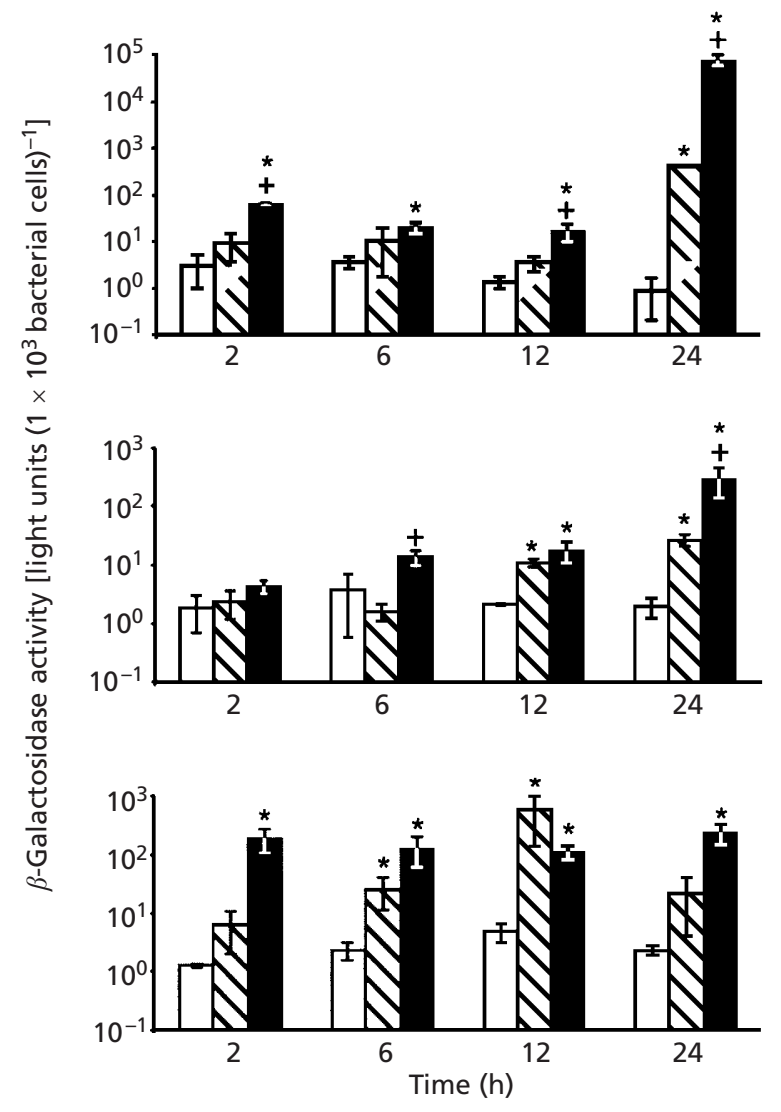

Fig. 2. Macrophage-induced lacZ expression of selected $B C G$ clones. Light units, generated using Galacto-Light Plus (Tropix), measuring the level of lac $Z$ expression ( $\beta$-galactosidase activity) by selected BCG clones after culturing for various times in 7H9 medium (open bars) and DMEM with serum (hatched bars), and post-infection of human monocyte cells (THP-1) (solid bars). Error bars are shown \pm SD for three separate cultures, each of which was assayed in triplicate. The significance values were obtained by a $t$-test, after transforming to $\log _{10}$ values. Asterisks indicate a statistically significant $(P<0.01)$ increase in $\beta$-galactosidase activity over $7 \mathrm{H} 9$-grown cells; plus symbols indicate a statistically significant $(P<0.01)$ increase in $\beta$-galactosidase activity over DMEM plus serum-grown cells. Clone 175 (top graph) contains $M$. tuberculosis sequence upstream from Rv0302, clone 176 (middle graph) contains $M$. tuberculosis sequence upstream from Rv2711 (IdeR) and clone 239 (bottom graph) contains $M$. tuberculosis sequence upstream from Rv1265. See Table 2 for more details.

that present in clone 166, which may account for the difference in their regulation.

Three clones (175, 176 and 239) were selected for more detailed analysis, using independent replicate cultures. The levels of $\beta$-galactosidase activity obtained from these clones, grown for different lengths of time in $7 \mathrm{H} 9$, in DMEM plus serum and in THP-1 cells, are shown in Fig. 2. At 12 and $24 \mathrm{~h}$ post-inoculation, all three clones showed a significantly higher level of $\beta$-galactosidase activity in THP-1-derived bacteria than that seen in bacteria grown in $7 \mathrm{H} 9$, with induction ratios at $24 \mathrm{~h}$ post-inoculation increased by two or more orders of magnitude. When compared to the bacteria grown in

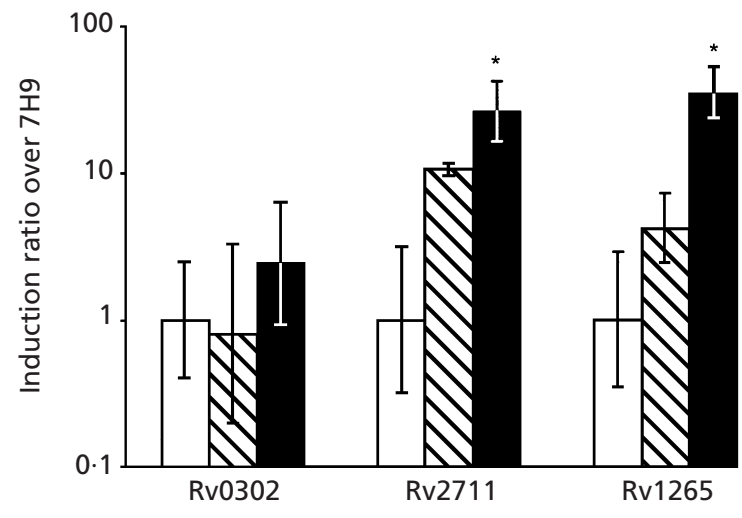

Fig. 3. Real-time RT-PCR assessment of the induction of selected genes in $M$. tuberculosis. Total RNA was obtained from M. tuberculosis H37Rv after culturing for $24 \mathrm{~h}$ in liquid $7 \mathrm{H} 9$ medium (open bars) or in DMEM plus serum (hatched bars), and $24 \mathrm{~h}$ post-infection of THP-1 monocytes at an m.o.i. of 10 (solid bars). The results are presented as the ratio of the amount of template produced under each condition to that produced by the 7H9-grown culture. Error bars are shown \pm SD for three separate cultures. The asterisks show the values that are significantly different $(P<0.01)$ from the $7 \mathrm{H} 9$ data. The genes tested correspond to the following promoter-probe clones: Rv0302, clone 175; Rv2711, clone 176; Rv1265, clone 239.

DMEM plus serum, the induction ratios for the three clones were less marked, suggesting the possibility that the serum was contributing to the induction. However, after $24 \mathrm{~h}$ incubation, clones 175 and 176 did show a significantly higher level of $\beta$-galactosidase activity in THP-1 cells than that seen when they were grown in DMEM plus serum [ratios $184(P=0 \cdot 0001)$ and $10 \cdot 8$ $(P=0.006)$, respectively]. Clone 239 showed an apparent induction with respect to serum that was similar to that of clone 176, but it was statistically less significant (ratio $10 \cdot 3, P=0 \cdot 07$ ). Although, quantitatively, these induction ratios do not all correlate with the less rigorous data in Table 2, both sets of data are consistent with the suggestion that $\beta$-galactosidase production in these clones is enhanced during macrophage infection.

\section{Quantitative real-time RT-PCR}

Reporter plasmids do not necessarily reflect accurately the regulation of the associated genes in the original host. Not only is the context of the promoter different, but gene dosage effects may also be significant. Therefore, the expression of genes Rv0302, Rv2711 and Rv1265 (corresponding to clones 175, 176 and 239, respectively) within macrophages was examined directly, using quantitative real-time RT-PCR. The levels of specific mRNA were assayed $24 \mathrm{~h}$ after infection of THP-1 cells by M. tuberculosis H37Rv; they were also assayed for controls cultured in DMEM plus serum and in 7H9 broth. Standardized amounts of RNA were used for comparison to the test samples, to allow estimation of the RNA present in each sample. Results $2 \mathrm{~h}$ postinfection were not significantly different from those at 24 $\mathrm{h}$ post-infection (results not shown). Fig. 3 shows the 
results expressed, for each gene, as the ratio of the estimated amount of template under each condition to that of the 7H9-grown culture. Differences in PCR efficiency made it impossible to standardize the data to the sig A control template; however, it was apparent that there was no significant difference in the $C_{T}$ value (the number of cycles required for detection of a signal) for $\operatorname{sig} A$ for each sample, which is consistent with the presence of similar amounts of RNA in each sample.

The data for Rv2711 (which encodes the iron-dependent regulator IdeR) suggest significant induction of Rv2711 expression in macrophage-grown cells when compared to those grown in $7 \mathrm{H} 9$ (26-fold induction; $P=0 \cdot 01$ ). This correlates with the enhanced $\beta$-galactosidase levels seen in the corresponding promoter-probe clone, 176 (Fig. 2). There also appeared to be induction of Rv2711 in cells grown in DMEM plus serum (11-fold induction; $P=0.02$ ), suggesting a degree of induction in the presence of serum. Correspondingly, there was less difference between the THP-1 and DMEM plus serum induction values, as was also found in the $\beta$-galactosidase assays for the corresponding promoterprobe clone.

The data for Rv1265 (which encodes a protein of unknown function) also indicate induction within the THP- 1 cells, when compared to the 7H9 and the DMEM plus serum controls (35-fold and eightfold induction, respectively; $P=0.005$ in both cases). There was no significant induction in the serum-containing control.

The other gene tested, Rv0302 (encoding a protein with unknown function and corresponding to clone 175), did not show any significant differences in its template level in any of the samples. The apparent induction of clone 175 , seen previously in the $\beta$-galactosidase assays, may therefore not reflect the true regulation of this promoter; alternatively, the contrast could arise from differences in the conditions of the two experiments. In particular it should be noted that the $\beta$-galactosidase assays (Fig. 2) were performed using reporter plasmids in BCG, whereas the RT-PCR data (Fig. 3) are from experiments with M. tuberculosis H37Rv. It is therefore possible that there is a strain-dependent difference in the regulation of this promoter.

\section{DISCUSSION}

The methodology described herein is an effective approach for identifying $M$. tuberculosis promoter fragments whose activity responds to changes in environmental conditions. The arrayed library represents a resource that is readily applicable to studying the effects of a wide range of environmental stimuli, including anaerobic growth and conditions that simulate dormancy, as well as the effects of the presence or absence of specific nutrients such as iron. The promoter-probe approach may enable the detection of promoters that are activated only transiently, which can be difficult to detect by mRNA-based methods. In addition, the use of reporter fusions facilitates the identification of promoters that exhibit modest changes in activity; for example, most of those identified by Triccas et al. (1999) and Barker et al. (1998) showed less than threefold induction. In this study, we used an in vitro screen for detecting enhanced expression of the lac $Z$ gene in the presence of acidified sodium nitrite, to enrich a library for a subset of the promoters that are potentially upregulated within macrophages.

Of the clones identified as exhibiting upregulated expression of lac $Z$ during the in vitro screens, 41 were further screened in macrophage infection studies and were subsequently characterized by sequencing. By virtue of their position on the M. tuberculosis genome, 15 of these clones were considered unlikely to represent genuine promoters (although it can not be ruled out), whereas 26 contained DNA sequence upstream from predicted genes in the correct orientation to drive transcription. Eleven clones showed evidence of induction in macrophages, indicating that the screening procedure used was successful in enriching for macrophage-regulated promoters. However, it must be emphasized that this strategy was not designed to obtain a complete set of all macrophage-regulated promoters those promoters responding to stimuli other than those used in this enrichment procedure will not be represented. Furthermore, the genes identified as adjacent to the macrophage-regulated promoters are not the only ones potentially regulated by them, as some of the promoters may control polycistronic operons.

Amongst the clones showing evidence of induction in THP-1 cells was one clone (166) that contains part of the promoter fragment for Rv0440 (bsp60/groEL2). The expression of Rv0440 has been shown to be upregulated during infection (Batoni et al., 1998). However, two further clones from our collection (278 and 291) with a shorter fragment upstream from Rv0440 did not show significant induction in THP-1 cells, suggesting that the region missing from these clones is necessary for effective induction.

In three cases (Rv0302, Rv2711 and Rv1265 corresponding to clones 175,176 and 239 , respectively), the expression of the gene controlled by the putative promoter was directly assayed by quantitative real-time RT-PCR. Promoter clone 175 (in BCG) showed significant $\beta$-galactosidase induction in THP-1 cells, whereas the RT-PCR data for the corresponding gene, Rv0302 (in M. tuberculosis $\mathrm{H} 37 \mathrm{Rv}$ ), showed no evidence of significant induction in macrophages under the conditions assayed. This may indicate that the induction of the promoter clone was an artefact. Alternatively, the contrast may be due to differences in the conditions used for the two experiments, including the possibility that the regulation of this gene differs between BCG and $M$. tuberculosis H37Rv. Such a difference has previously been observed with the response regulator gene $m \operatorname{tr} A$, where an $m t r A-g f p$ transcriptional fusion in BCG was induced on entry into macrophages, but showed constitutive expression in M. tuberculosis H37Rv (Via et al., 1996; Zahrt \& Deretic, 2000). The function of the product of gene Rv0302 is not known, although it has 
some sequence similarity to regulatory proteins such as AcrAB of E. coli.

The data obtained from the $\beta$-galactosidase assays of promoter clone 239 and the real-time RT-PCR of its corresponding gene, Rv1265, suggest that the expression of this gene is indeed upregulated during infection of macrophages by M. tuberculosis. The function of the predicted product of Rv1265 is not known.

Consistent evidence of macrophage induction was also seen with promoter clone 176 and its corresponding gene, Rv2711. Rv2711 encodes the iron-dependent repressor IdeR (Schmitt et al., 1995), which has been shown to be a homologue of the diphtheria toxin repressor (DtxR) and is responsible for repressing siderophore biosynthesis in the presence of iron. However, it is necessary to distinguish the regulatory effects of IdeR on other genes from factors that may influence the expression of ideR. Whilst there is no published evidence of the regulation of expression of ideR itself, our results suggest that it is upregulated within macrophages and possibly also in serum-containing medium. This upregulation could be a consequence of iron deprivation, which is likely to occur in both situations. However, there is not a clear role for enhanced production, under low iron conditions, of a negative regulator of iron uptake processes.

Conversely, Gold et al. (2001) have shown that IdeR is a pleiotropic regulator of gene expression in M. tuberculosis, capable of positive as well as negative regulation, with many of the potential IdeR-regulated genes having no obvious relationship to iron metabolism. This raises the possibility that iron limitation may be a recognition signal for the intracellular environment, resulting in changes in other characteristics, such as membrane structure (Gold et al., 2001). Furthermore, Dussurget et al. (1996) found that M. smegmatis ideR mutants are more sensitive to oxidative stress, suggesting that IdeR couples iron metabolism to the oxidative-stress response, although Gold et al. (2001) did not find IdeR boxes upstream from $M$. tuberculosis genes annotated as oxidative stress detoxifying enzymes. The potential for a broader role of IdeR in regulating mycobacterial gene expression provides a possible role for enhanced expression of this gene in such situations. The role of IdeR, and the nature of its regulation, therefore warrants further study, as does the function and regulation of Rv1265, which is also a candidate as a possible virulence factor. The use of allelic replacement to establish strains lacking these genes, or producing modified proteins similar to the iron-independent variant DtxR (Sun et al., 1998; Manabe et al., 1999), and investigation of the ability of such mutants to survive and grow within the macrophage, would enable investigation of the roles of these genes in intracellular existence.

Further screening of the clone library detailed in this study under alternative in vitro conditions, and further characterization of the identified clones, will be a valuable way of identifying not only potential virulence determinants but also of identifying mycobacterial promoters that respond, even transiently, to different environmental conditions.

\section{ACKNOWLEDGEMENTS}

R. J.H. was supported by a BBSRC/Glaxo Wellcome Industrial CASE studentship, and we are grateful to the Wellcome Trust for its additional support. We are grateful to Ken Duncan for his encouragement and support, to Graham Stewart (Dept of Infectious Diseases and Microbiology, Imperial College School of Medicine, St Mary's Campus, Norfolk Place, Paddington, London W2 1PG, UK) for the provision of vector pUS1781, and to Sue Shaw-Hawkins for sequencing.

\section{REFERENCES}

Arruda, S., Bomfim, G., Knights, R., Huima-Byron, T. \& Riley, L. W. (1993). Cloning of an M. tuberculosis DNA fragment associated with entry and survival inside cells. Science 261, 1454-1457.

Barker, L. P., Brooks, D. M. \& Small, P. L. C. (1998). The identification of Mycobacterium marinum genes differentially expressed in macrophage phagosomes using promoter fusions to green fluorescent protein. Mol Microbiol 29, 1167-1177.

Batoni, G., Maisetta, G., Florio, W., Freer, G., Campa, M. \& Senesi, S. (1998). Analysis of the Mycobacterium bovis hsp60 promoter activity in recombinant Mycobacterium avium. FEMS Microbiol Lett 169, 117-124.

Berthet, F. X., Lagranderie, M., Gounon, P. \& 9 other authors (1998). Attenuation of virulence by disruption of the Mycobacterium tuberculosis erp gene. Science 282, 759-762.

Cole, S. T., Brosch, R., Parkhill, J. \& 39 other authors (1998). Deciphering the biology of Mycobacterium tuberculosis from the complete genome sequence. Nature 393, 537-544.

Collins, D. M. \& Gicquel, B. (2000). Genetics of mycobacterial virulence. In Molecular Genetics of Mycobacteria, pp. 265-278. Edited by G. F. Hatfull \& W. R. Jacobs. Washington, DC: American Society for Microbiology.

Collins, D. M., Kawakami, R. P., Delisle, G. W., Pascopella, L., Bloom, B. R. \& Jacobs, W. R. (1995). Mutation of the principal $\sigma$ factor causes loss of virulence in a strain of the Mycobacterium tuberculosis complex. Proc Natl Acad Sci U S A 92, 8036-8040.

Dellagostin, O. A., Esposito, G., Eales, L.-J., Dale, J. W. \& McFadden, J. (1995). Activity of mycobacterial promoters during intracellular and extracellular growth. Microbiology 141, 17851792.

Dussurget, O., Rodriguez, M. \& Smith, I. (1996). An ideR mutant of Mycobacterium smegmatis has derepressed siderophore production and an altered oxidative-stress response. Mol Microbiol 22, 535-544.

Gold, B., Rodriguez, G. M., Marras, S. A. E., Pentecost, M. \& Smith, I. (2001). The Mycobacterium tuberculosis IdeR is a dual functional regulator that controls transcription of genes involved in iron acquisition, iron storage and survival in macrophages. Mol Microbiol 42, 851-865.

Gomez, M. \& Smith, I. (2000). Determinants of mycobacterial gene expression. In Molecular Genetics of Mycobacteria. pp. 111-129. Edited by G. F. Hatfull \& W. Jacobs. Washington, DC: American Society for Microbiology.

Graham, J. E. \& Clark-Curtiss, J. E. (1999). Identification of Mycobacterium tuberculosis RNAs synthesized in response to phagocytosis by human macrophages by selective capture of transcribed sequences (SCOTS). Proc Natl Acad Sci USA 96, 11554-11559. 
Lee, B.-Y. \& Horwitz, M. A. (1995). Identification of macrophage and stress-induced proteins of Mycobacterium tuberculosis. I Clin Invest 96, 245-249.

Manabe, Y. C., Saviola, B. J., Sun, L., Murphy, J. R. \& Bishai, W. R. (1999). Attenuation of virulence in Mycobacterium tuberculosis expressing a constitutively active iron repressor. Proc Natl Acad Sci U S A 96, 12844-12848.

Manganelli, R., Dubnau, E., Tyagi, S., Kramer, F. R. \& Smith, I. (1999). Differential expression of 10 sigma factor genes in Mycobacterium tuberculosis. Mol Microbiol 31, 715-724.

McKinney, J. D., Honer zu Bentrup, K., Muñoz-Elias, E. J. \& 7 other authors (2000). Persistence of Mycobacterium tuberculosis in macrophages and mice requires the glyoxylate shunt enzyme isocitrate lyase. Nature 406, 735-738.

Plum, G. \& Clark-Curtiss, J. E. (1994). Induction of Mycobacterium avium gene expression following phagocytosis by human macrophages. Infect Immun 62, 476-483.

Ranes, M. G., Rauzier, J., Lagranderie, M., Gheorghiu, M. \& Gicquel, B. (1990). Functional analysis of pAL5000, a plasmid from Mycobacterium fortuitum: construction of a 'mini' Mycobacterium-Escherichia coli shuttle vector. J Bacteriol 172, 27932797.

Rindi, L., Lari, N. \& Garzelli, C. A. (1999). Search for genes potentially involved in Mycobacterium tuberculosis virulence by mRNA differential display. Biochem Biophys Res Commun 258, 94-101.

Schmitt, M. P., Predich, M., Doukhan, L., Smith, I. \& Holmes, R. K. (1995). Characterization of an iron-dependent regulatory protein (IdeR) of Mycobacterium tuberculosis as a functional homolog of the diphtheria toxin repressor (DtxR) from Corynebacterium diphtheriae. Infect Immun 63, 4284-4289.

Stover, C. K., de la Cruz, V. F., Fuerst, T. R. \& 11 other authors (1991). New use of BCG for recombinant vaccines. Nature 351, $456-460$
Sun, L., vanderSpek, J. \& Murphy, J. R. (1998). Isolation and characterization of iron-independent positive dominant mutants of the diphtheria toxin repressor DtxR. Proc Natl Acad Sci US A 95, 14985-14990.

Timm, J., Gomez, M. \& Smith, I. (1999). Gene expression and regulation. In Mycobacteria: Molecular Biology and Virulence, pp. 59-92. Edited by C. Ratledge \& J. W. Dale. Oxford: Blackwell Science.

Triccas, J. A., Berthet, F.-X., Pelicic, V. \& Gicquel, B. (1999). Use of fluorescence induction and sucrose counterselection to identify Mycobacterium tuberculosis genes expressed within host cells. Microbiology 145, 2923-2930.

Triccas, J. A., Britton, W. J. \& Gicquel, B. (2001). Isolation of strong expression signals of Mycobacterium tuberculosis. Microbiology 147, 1253-1258.

Tyagi, A. K., Das Gupta, S. K. \& Jain, S. (2000). Gene expression: reporter gene technologies. In Molecular Genetics of Mycobacteria, pp. 131-147. Edited by G. F. Hatfull \& W. R. Jacobs. Washington, DC: American Society for Microbiology.

Via, L. E., Curcic, R., Mudd, M. H., Dhandayuthapani, S., Ulmer, R. J. \& Deretic, V. (1996). Elements of signal transduction in Mycobacterium tuberculosis: in vitro phosphorylation and in vivo expression of the response regulator MtrA. J Bacteriol 178, 3314-3321.

Zahrt, T. C. \& Deretic, V. (2000). An essential two-component signal transduction system in Mycobacterium tuberculosis. J Bacteriol 182, 3832-3838.

Zhang, Y. \& Young, D. B. (1993). Molecular mechanisms of isoniazid: a drug at the front line of tuberculosis control. Trends Microbiol 1, 109-113.

Received 16 October 2001; revised 8 January 2002; accepted 21 January 2002. 